\title{
The Effectiveness of Interest Rate Parity
}

\author{
JINCHENG ZHANG AND YING DOU
}

\section{Abstract}

This paper provides an investigation as to whether there has been any improvement on the effectiveness of IRP in forecasting exchange rates in threemonth periods. With AUD being the base currency, the research is conducted using nine foreign currency proxies, namely USD, JPY, GBP, CHF, NZD, CAD, HKD, SGD and CNY. Historical exchange rates of AUD over the nine foreign currencies and three-month interest rates in the ten countries from 1 January 1995 to 30 December 2008 are collected and computed. According to our results, although there is evidence suggesting that IRP generally holds, its quality does not appear to have improved in recent years. Indeed, we found strong evidence indicating that the quality of IRP is not related to the time horizon. One possible explanation to this finding might be that the recent financial crisis has triggered significant government intervention and brought incredible currency risk, deteriorating the quality of IRP.

\section{Introduction}

The Interest Rate Parity (IRP) condition is a commonly employed technique in making exchange rates forecasts. Forecasts under this condition are made by inputting the spot exchange rates and the interest rates in the domestic and foreign countries respectively. Therefore the reliability of this technique is highly related to how the two interest rates are affected. In recent years, as the world becomes more internationally related, interest rates are no longer determined solely by countries' domestic economic factors. Since the quality of IRP is positively connected to the level of the global financial market integration, it is reasonable to expect an improvement in the quality of IRP compared with a decade ago. 
This paper aims to test whether the performance of IRP in forecasting exchange rates in three-month periods has improved recently. This requires quantitative measures. With AUD being the domestic currency, nine currencies (including USD in the US, JPY in Japan, GBP in the UK, CHF in Switzerland, NZD in New Zealand, CAD in Canada, HKD in Hong Kong, SGD in Singapore, and CNY in China) are used as foreign currency proxies over which exchange rates of AUD are to be forecasted. Data of spot exchange rates, domestic interests and foreign interests for the period 1995-2008 were collected from reserve banks of the ten countries in discussion.

\section{Theoretical Arguments}

Generally there are two versions of IRP - covered and uncovered. Before examining IRP, we made an assumption that forward parity always holds (ie. $\mathrm{E}\left[\mathrm{S}_{\mathrm{t}}^{\mathrm{d} / \mathrm{f}}\right]=\mathrm{F}_{\mathrm{t}}^{\mathrm{d} / \mathrm{f}}$ ). For this to be true, investors have to be risk neutral so that risk premium is equal to zero. Although this "unbiasedness hypothesis" was rejected by many finance literature (Chinn and Meredith, 2005), it was first argued by Mussa (1979) and tested by Froot and Thaler (1990) that the proposition may be better applied at longer horizons. ${ }^{1}$ In the real world, many macroeconomical models assume a strong version of perfect capital market. Therefore, for ease of calculation and comparison, we combine forward parity and covered IRP (CIRP), making the model we are testing to be:

$$
\frac{E\left[S_{t}^{d / f}\right]}{S_{0}^{d / f}}=\left(\frac{1+i_{d}}{1+i_{f}}\right)^{t}
$$

This is effectively the expression of Uncovered IRP (UIRP). Because historical forward rates of exchange over various foreign currencies are not easily accessible to the general public, expression (1) is a commonly used model for market-based forecasts of exchange rates. It presents a simple way of forecasting exchange rates, and it is easy to work out its forecast accuracy by comparing $E\left[S_{t}^{d / f}\right]$ and $S_{t}^{d / f}$.

In order to test whether this equation works better than in previous times, we first examine whether it generally holds. If it does, $E\left[S_{t}{ }_{t}^{d / f}\right]$ calculated from equation (1) will be close to the actual. From this, we have the following hypothesis:

1 Exceptions include Flood and Rose's (1996) results for intra-EMS exchange rates, and Frankel and Poonawala's (2004) findings for emerging markets. Interestingly, Chaboud and Wright (2003) found that UIRP holds for major currencies at extremely high frequencies, such as intraday. 
$\mathrm{H}_{0}: \mathrm{S}_{\mathrm{t}}^{\mathrm{d} / \mathrm{f}}=\mathrm{E}\left[\mathrm{S}_{\mathrm{t}}^{\mathrm{d} / \mathrm{f}}\right]=\frac{E\left[S_{t}^{d / f}\right]}{S_{0}{ }^{d / f}}=\left(\frac{1+i_{d}}{1+i_{f}}\right)^{t}$, where $\mathrm{T}_{\mathrm{t}}-\mathrm{T}_{\mathrm{t}-\mathrm{l}}=3$ months

We expect this to hold because if rates of return from investments of two countries are not the same, funds will move to a country with the more attractive rate. As we assume that forward price is an accurate predictor of future spot price, equation (1) will also hold. Recent research suggests that UIRP tends to hold for over medium to long periods (Flood and Taylor, 1997; Cochrane, 1999; Alexius, 2001; Chinn and Meredith, 2004 and 2005; Chinn, 2006; Zhang, 2006). However, it must be noted that the majority of current support in favour of the standard, linear, specification of UIRP is restricted to major floating currencies and three-year or longer horizons (Mehl and Cappiello, 2007). As our research is vis-à-vis three-month periods and includes emerging markets, it is possible that the alternative hypothesis works. That is:

$\mathrm{H}_{\mathrm{A}}: \mathrm{S}_{\mathrm{t}}^{\mathrm{d} / \mathrm{f}} \mathrm{E}\left[\mathrm{S}_{\mathrm{t}}^{\mathrm{d} / \mathrm{f}}\right]=\frac{E\left[S_{t}{ }^{d / f}\right]}{S_{0}{ }^{d / f}}=\left(\frac{1+i_{d}}{1+i_{f}}\right)^{t}$, where $\mathrm{T}_{\mathrm{t}}-\mathrm{T}_{0}=3$ months

This could be the case even if the CIRP itself holds, because forward parity may not hold in the real world. After testing whether IRP generally holds, we can then further test whether it has become more accurate recently. If it does, the absolute forecast errors of IRP should be generally decreasing from 1995 to 2008. So we have the second null hypothesis:

$\mathrm{H}_{0}: \frac{E\left[S_{t}^{d / f}\right]}{S_{0}{ }^{d / f}}=\left(\frac{1+i_{d}}{1+i_{f}}\right)^{t}$ decreases over the period of 1995-2008

Recently, there has been a trend of rapid integration in the world, evidenced by more widespread free trade agreements in goods market and the increases in cross-border financing in financial markets. With the reduction of barriers and the increase in integration, it is reasonable to expect that a financial market has become more efficient recently. This means numerous investors can respond faster to market mispricing, making CIRP hold better. Due to our assumption of $E\left[S_{t}^{d / f}\right]=F_{t}^{d / f}$, it also means that model (1) (ie. UIRP) should work better than previously. If it does not, the alternative hypothesis applies: 
$\mathrm{HA}: \frac{E\left[S_{t}^{d / f}\right]}{S_{0}{ }^{d / f}}=\left(\frac{1+i_{d}}{1+i_{f}}\right)^{t}$ does not decrease over the period 1995-2008

This includes situations where the absolute forecast errors increase, remain the same, or move randomly without obvious trends over time. Because IRP forecasts exchange rates by inputting spot exchange rate and the interest rates in the two countries, fluctuations in interest rates can significantly affect the accuracy. When interest rates are highly manipulated by the governments, the quality of IRP may deteriorate. Because of the economic recession since 2008 and its signs in previous years, governments or central banks of many countries started to set interest rates artificially. This raises the potential of a less accurate IRP.

\section{Empirical Evidence}

\section{Data Collection}

In order to test the forecast accuracy of IRP in three-month intervals, we use AUD as the domestic currency and choose nine main currencies as foreign currency proxies (namely, USD, JPY, GBP, CHF, NZD, CAD, HKD, SGD and CNY). We then retrieved historical daily spot exchange rates of AUD over the nine foreign currencies and three-month interest rates in the ten countries on the first days of January, April, July and October from 1 January 1995 to 30 December 2008. For non-trading days (eg. 1 January), we apply the rates on the closest day before that date. It is often difficult to locate data on interest rates and spot foreign exchange rates at many time horizons that are time synchronous. Therefore, we ignore time differences over the world and assume that all countries use Australian Eastern Standard Time. So interest rates on a foreign reserve bank are treated to be quoted in accordance with Sydney time, making allowances for possible time discrepancies. All exchange rates are in the form of direct quote with AUD as the numerator. All interests are converted to periodic rates over three months.

According to expression (1), if $i_{d}>i_{f^{\prime}}$ then $E\left[S_{t}^{d / f}\right]>S_{t}^{d / f}$. In other words, if IRP holds, higher interest rate currency should depreciate and vice versa. This worked for all currency pairs we examined. The relationship between AUD and USD serves as a good example in this matter. From 1 January 1995 to 1 April 1997, AUD boasted higher interest rates and depreciated. From 1 July 1997 to 
1 October 1998, USD boasted higher interest rates and depreciated. This also applies to other time periods, with slight deviations allowed. However, the relationship between AUD and NZD is an exception. Over the 1995-2008 period, $i_{\text {AUD }}$ is generally lower than $i_{\text {NZD' }}$ while AUD has generally depreciated against AUD.
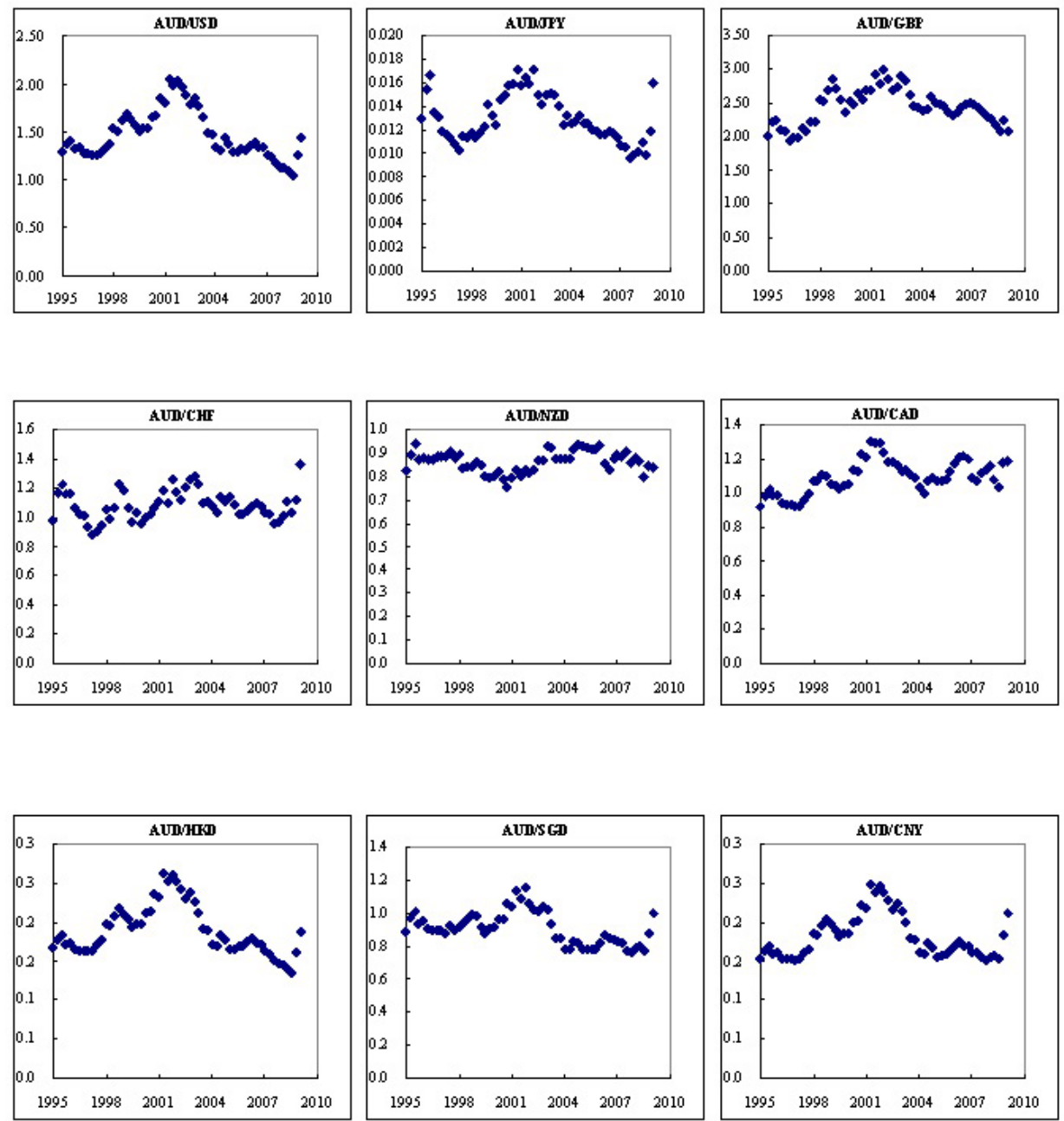

Figure 1: Exchange Rates of Australian Dollar over the period 1 January 1995 to 31 December 2008 (56 observatios). This figure plots the series of exchange close-rates on the first day of each quarter of the Australian Dollar (AUD) vs the US Dollar (USD), Japanese Yen (JPY), British Pound (GBP), Swiss Franc (CHF), New Zealand Dollar (NZD), Canadian Dollar (CAD), Hongkong Dollar (HKD), Singaporean Dollar (SHD) and Chinese Yuan (CNY). 
We then use expression (1) and the above data to forecast future spot rates. If the forecasts are accurate, the scatter plot graph with expected spot rates $E\left[S_{t}^{d / f}\right]$ being $y$-axis and actual spot rates $S_{t}^{d / f}$ being the $x$-axis should have an intercept of 0 and a slope of unity. Also, if IRP works better in these years, the absolute forecast errors should be decreasing over time. Thus, the scatter plot graph with absolute forecast errors as the $\mathrm{y}$-axis and dates as the $\mathrm{x}$-axis should be negatively sloped.

\section{Empirical Results}

Table 1 summarises all the expected exchange rates from calculation. Table 2 and Table 3 show the forecast error and absolute error respectively. According to Figure 2, with actual exchange rates being the x-axis and expected rates being the $y$-axis, almost all of the currency pairs provide trendlines with slopes equal to 1 and intercepts close to 0 . Therefore the IRP condition accurately forecasted exchange rates, with the only exception of AUD/JPY, whose deviations are fairly statistically significant. 
The Effectiveness of Interest Rate Parity

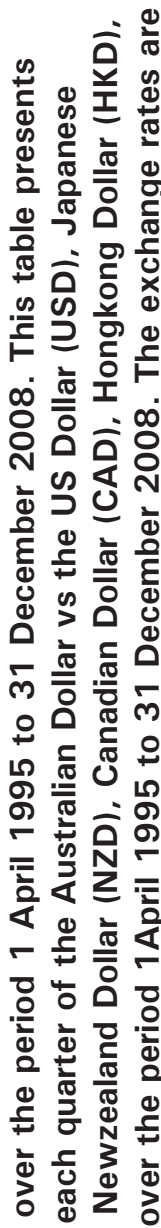

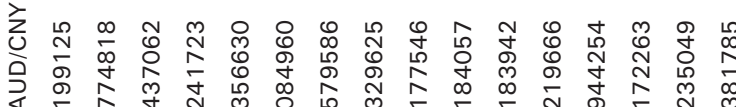
今̂ ○

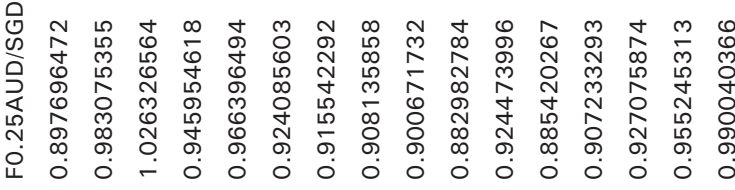

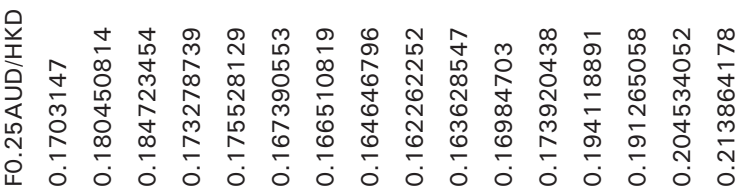

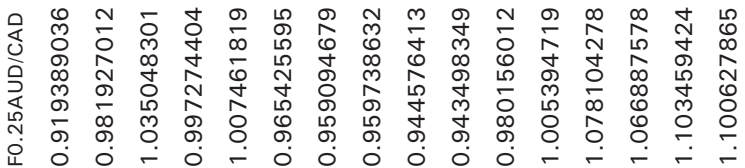

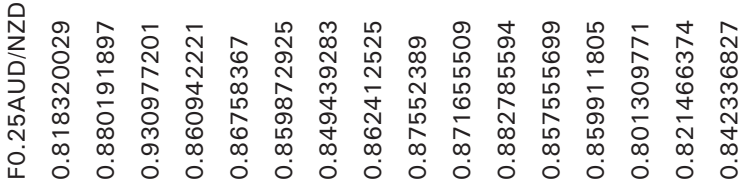

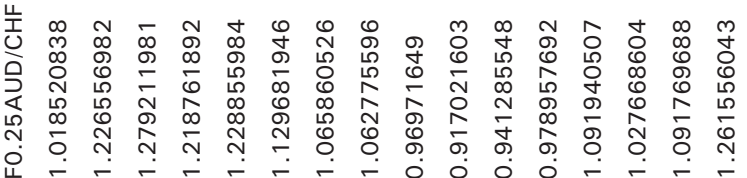

훙

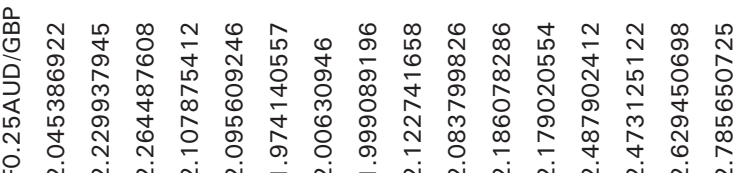

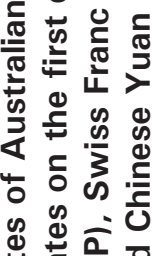

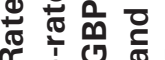

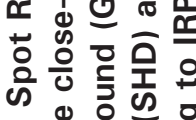

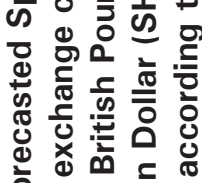

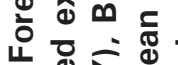

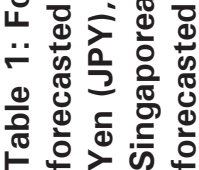

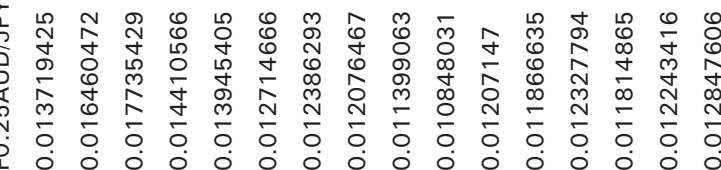

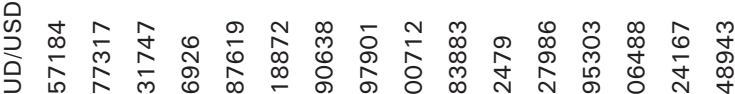

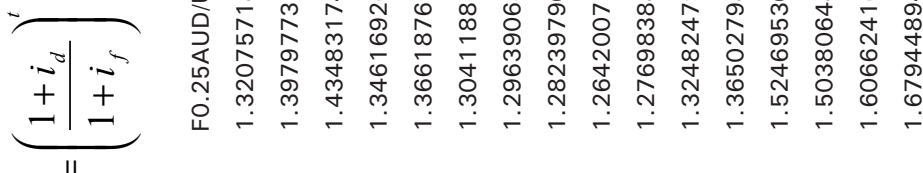

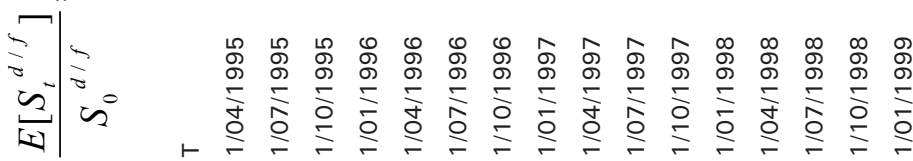


The ANU Undergraduate Research Journal Volume Two 2010

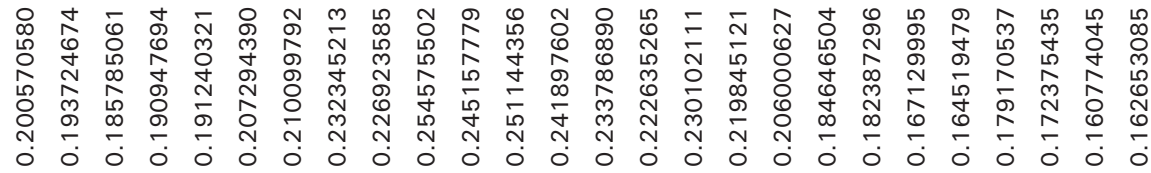

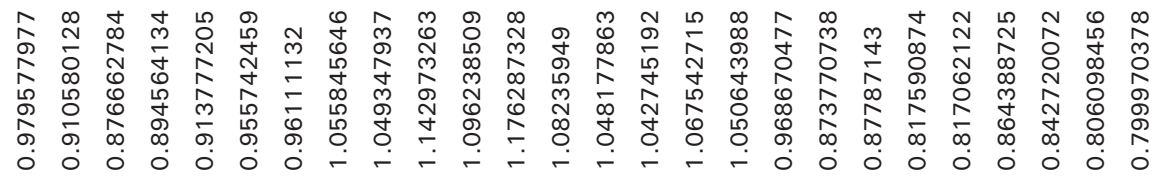

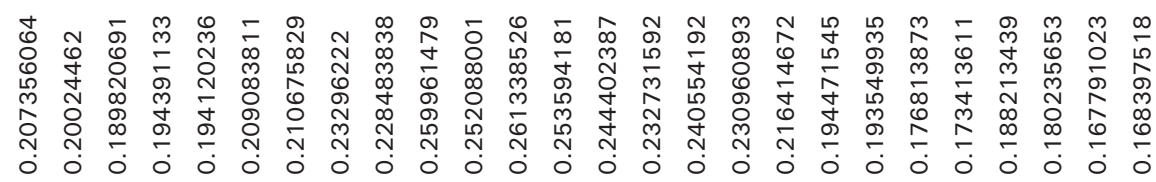

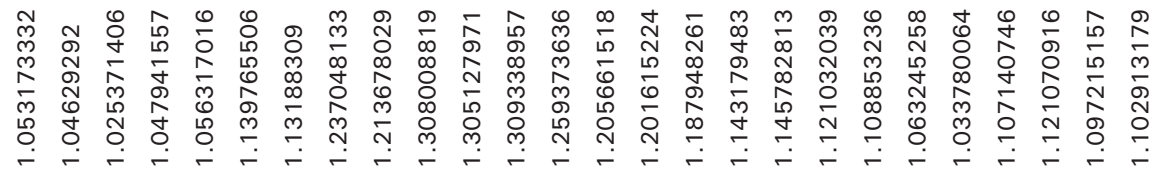
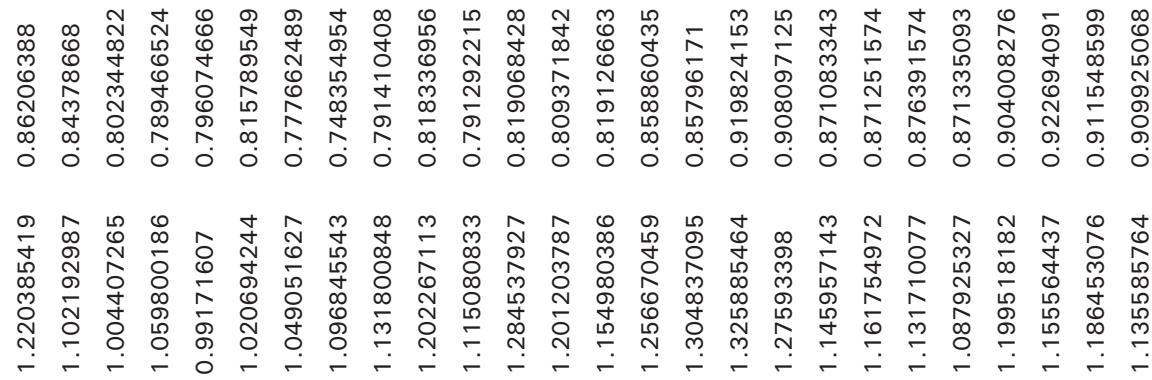

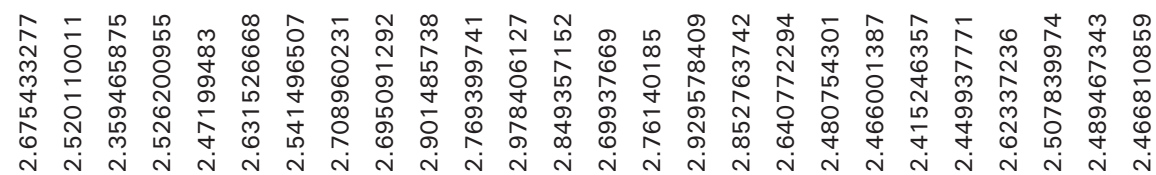
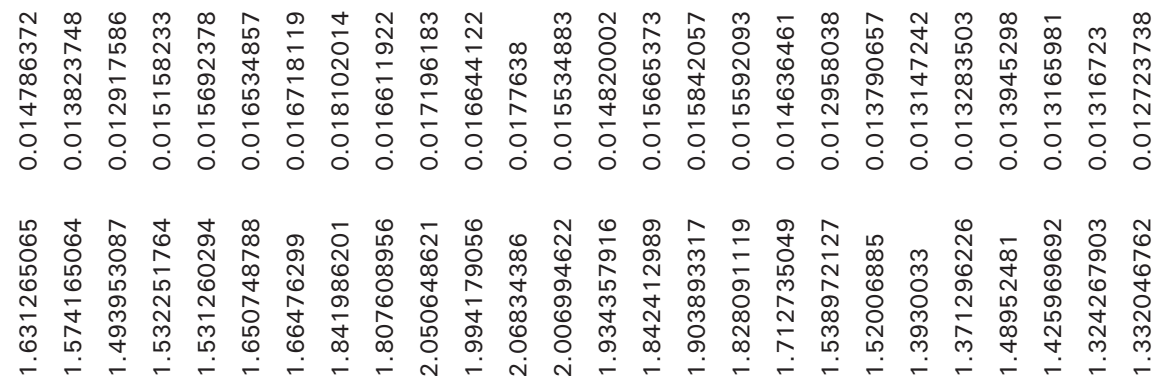
The Effectiveness of Interest Rate Parity

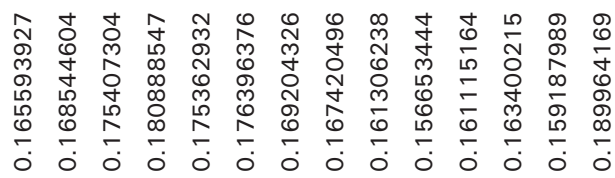

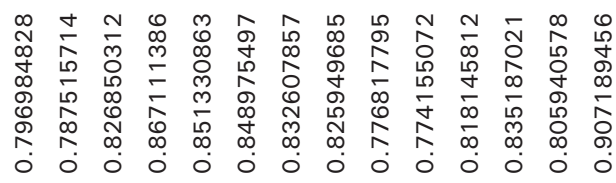

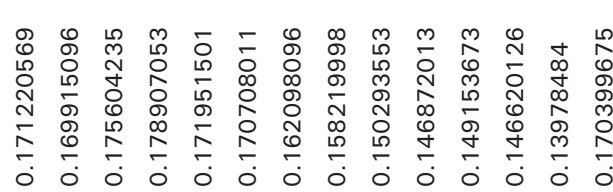

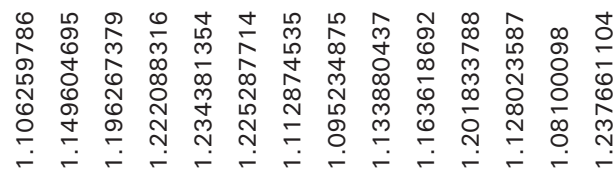

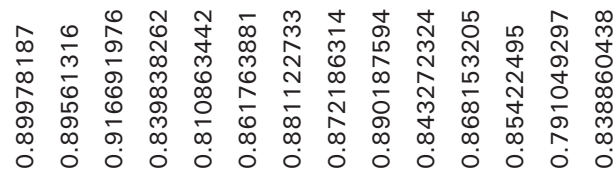

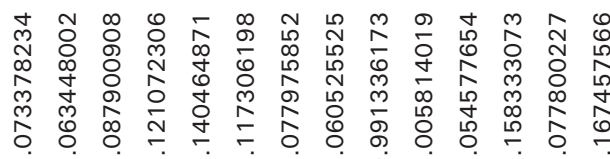

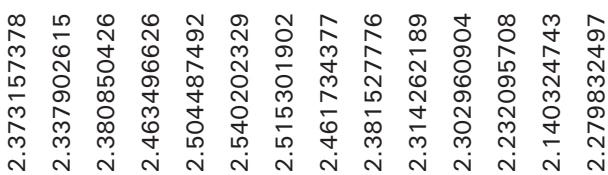

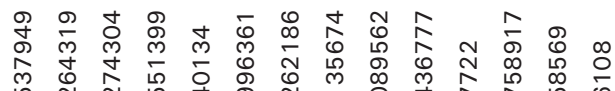
N

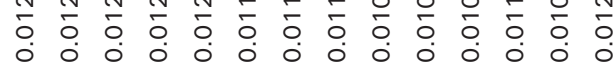
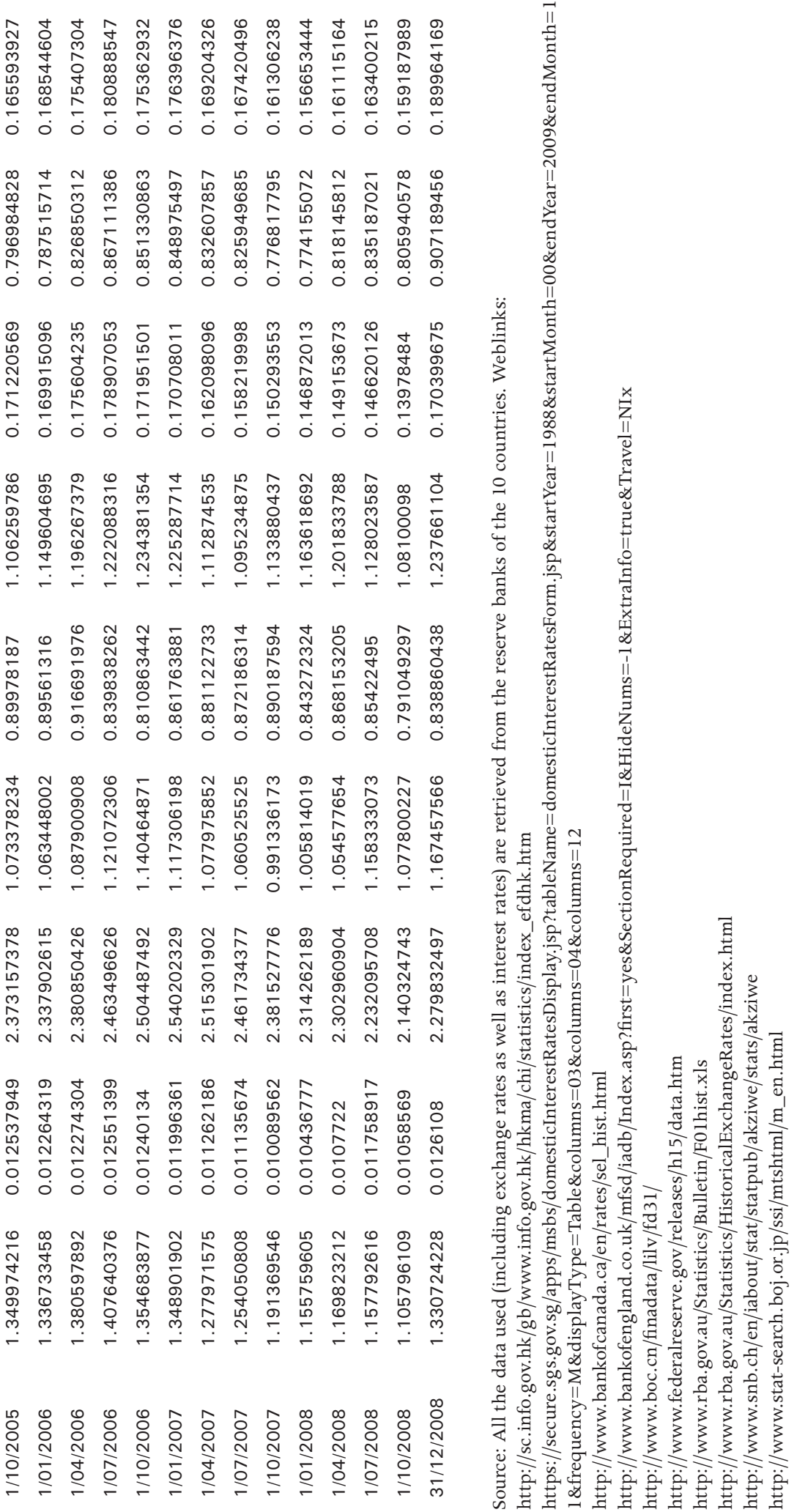
The ANU Undergraduate Research Journal Volume Two 2010

Table 2: Forecast Error (\%) $=$ (Forecast-Spot)/Spot over the period 1 April 1995 to 31 December 2008.

$\begin{array}{lllll} & 1995-2001 & & 2002-2008 & \\ & \text { Mean } & \text { Median } & \text { Mean } & \text { Median } \\ \text { AUD/USD } & -0.0098 & -0.0046 & 0.0428 & 0.0516 \\ \text { AUD/JPY } & 0.0475 & 0.0448 & 0.0602 & 0.0682 \\ \text { AUD/GBP } & -0.0148 & -0.0072 & 0.0246 & 0.0262 \\ \text { AUD/CHF } & 0.0310 & 0.0117 & 0.0420 & 0.0573 \\ \text { AUD/NZD } & -0.0112 & -0.0185 & -0.0100 & -0.0042 \\ \text { AUD/CAD } & -0.0007 & 0.0115 & 0.0304 & 0.0277 \\ \text { AUD/HKD } & -0.0198 & -0.0105 & 0.0283 & 0.0328 \\ \text { AUD/SGD } & -0.0053 & -0.0107 & 0.0326 & 0.0301 \\ \text { AUD/CNY } & 0.0096 & 0.0136 & 0.0436 & 0.0556\end{array}$

Table 3: Absolute Error $=\frac{E\left[S_{t}^{d / f}\right]}{S_{0}^{d / f}}=\left(\frac{1+i_{d}}{1+i_{f}}\right)^{t}$ over the period 1 April 1995 to 31 December 2008.

$\begin{array}{lllll} & 1995-2001 & & 2002-2008 & \\ & \text { Mean } & \text { Median } & \text { Mean } & \text { Median } \\ \text { AUD/USD } & 0.0419 & 0.0367 & 0.0602 & 0.0612 \\ \text { AUD/JPY } & 0.0824 & 0.0894 & 0.0802 & 0.0692 \\ \text { AUD/GBP } & 0.0485 & 0.0544 & 0.0367 & 0.0347 \\ \text { AUD/CHF } & 0.0702 & 0.0710 & 0.0622 & 0.0573 \\ \text { AUD/NZD } & 0.0308 & 0.0294 & 0.0286 & 0.0217 \\ \text { AUD/CAD } & 0.0336 & 0.0298 & 0.0409 & 0.0321 \\ \text { AUD/HKD } & 0.0427 & 0.0321 & 0.0517 & 0.0496 \\ \text { AUD/SGD } & 0.0415 & 0.0338 & 0.0493 & 0.0375 \\ \text { AUD/CNY } & 0.0421 & 0.0399 & 0.0621 & 0.0644\end{array}$

Table 4: Regression Output for Plots of $E\left(S_{t}^{A U D / f}\right)$ over $S_{t}^{A U D / f}$ over the period 1 April 1995 to 31 December 2008

$\begin{array}{lllll} & \text { Obs } & \text { Intercept } & \text { Slope } & \text { R-squared } \\ \text { AUD/USD } & 56 & 0.1254 & 0.9297 & 0.8610 \\ \text { T-stats } & & 1.6555 & 18.2921 & \\ \text { AUD/JPY } & 56 & 0.0026 & 0.8505 & 0.6931 \\ \text { T-stats } & & 2.5543 & 11.0432 & \\ \text { AUD/GBP } & 56 & 0.3877 & 0.8452 & 0.7554 \\ \text { T-stats } & & 2.4116 & 12.9127 & \\ \text { AUD/CHF } & 56 & 0.4432 & 0.6245 & 0.4146\end{array}$




$\begin{array}{lclll}\text { T-stats } & & 4.0351 & 6.1848 & \\ \text { AUD/NZD } & 56 & 0.2641 & 0.6825 & 0.5230 \\ \text { T-stats } & & 3.4454 & 7.6943 & \\ \text { AUD/CAD } & 56 & 0.1295 & 0.8961 & 0.7520 \\ \text { T-stats } & & 1.6854 & 12.7975 & \\ \text { AUD/HKD } & 56 & 0.0178 & 0.9085 & 0.8593 \\ \text { T-stats } & & 1.8553 & 18.1628 & \\ \text { AUD/SGD } & 56 & 0.1521 & 0.8449 & 0.7546 \\ \text { T-stats } & & 2.4730 & 12.5465 & \\ \text { AUD/CNY } & 56 & 0.0146 & 0.9448 & 0.8530 \\ \text { T-stats } & & 1.4940 & 17.7014 & \end{array}$
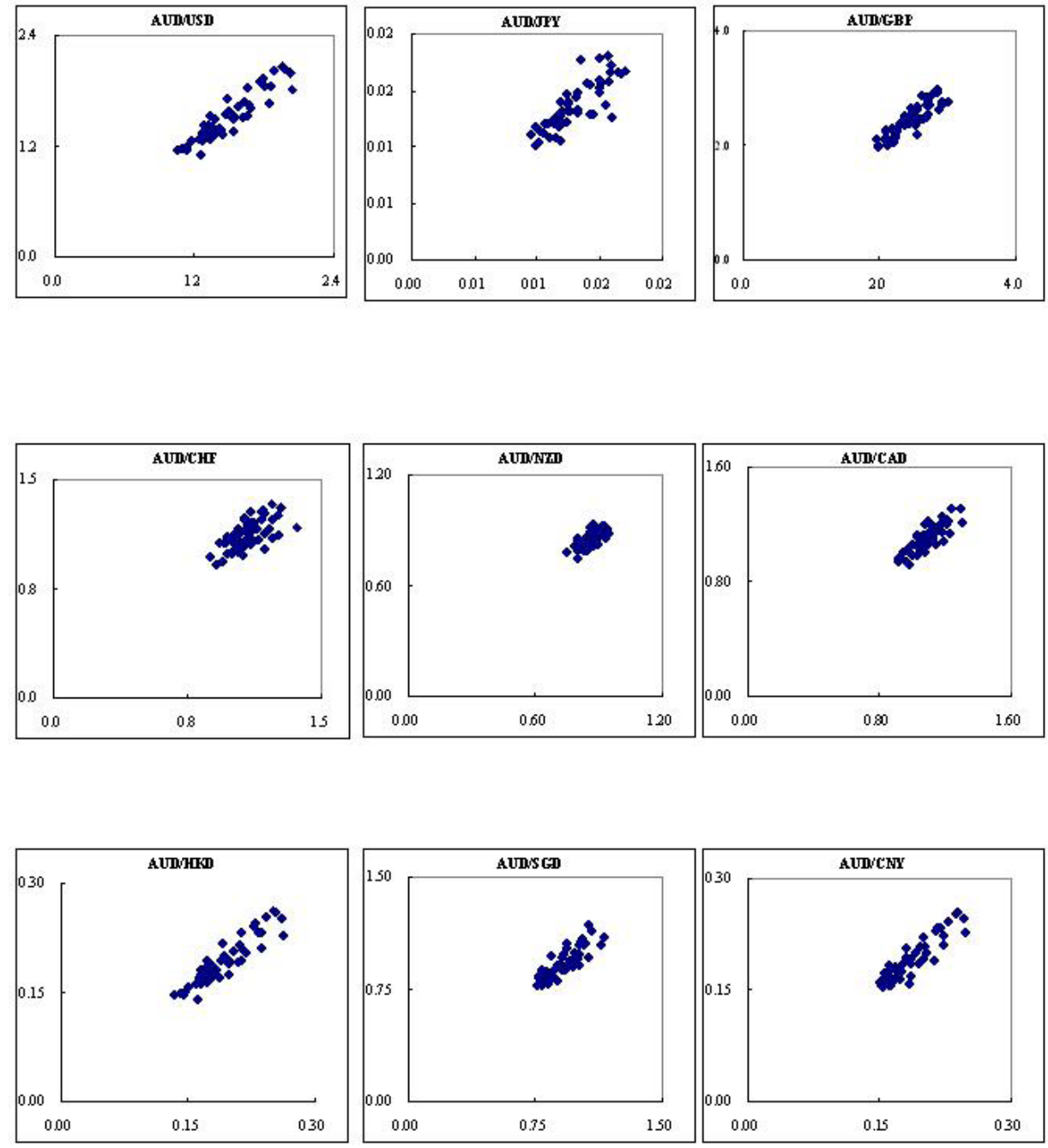

Figure 2: Expected Spot Rates (y-axis) vs. Actual Spot Rates (x-axis) over the period 1 April 1995 to 31 December 2008 (55 observations). 
The regression output in Table 4 further supported this idea. Apart from AUD/ $\mathrm{NZD}$ and AUD/CHF, the currency pairs give an average slope of 0.9 and an average intercept of 0.02. For AUD/NZD and AUD/CHF, the slopes are both below 0.7 and the intercepts are both above 0.2, providing unfavourable evidence. Further, the fact that AUD/JPY has a slope of 0.85 and an intercept less than 0.01 does not necessarily mean the output from AUD/JPY is providing favourable evidence. Its R-square of 0.6931 reveals that only less than $70 \%$ of the total observations can be explained. Nevertheless, overall, the null was found to hold. Thus, one can safely conclude that the IRP works on average and the first $\mathrm{H}_{0}$ holds.

Figure 3 is comprised of nine graphs representing the absolute forecast errors in the nine currency pairs. If the quality of UIRP has improved, most graphs should look negatively sloped. But in Figure 2, none of the nine pairs shows an obvious downward trend. Indeed, the trendlines in graphs of AUD/USD, AUD/ HKD and AUD/CNY seem to be even upward sloping, providing a completely opposite result from that expected.
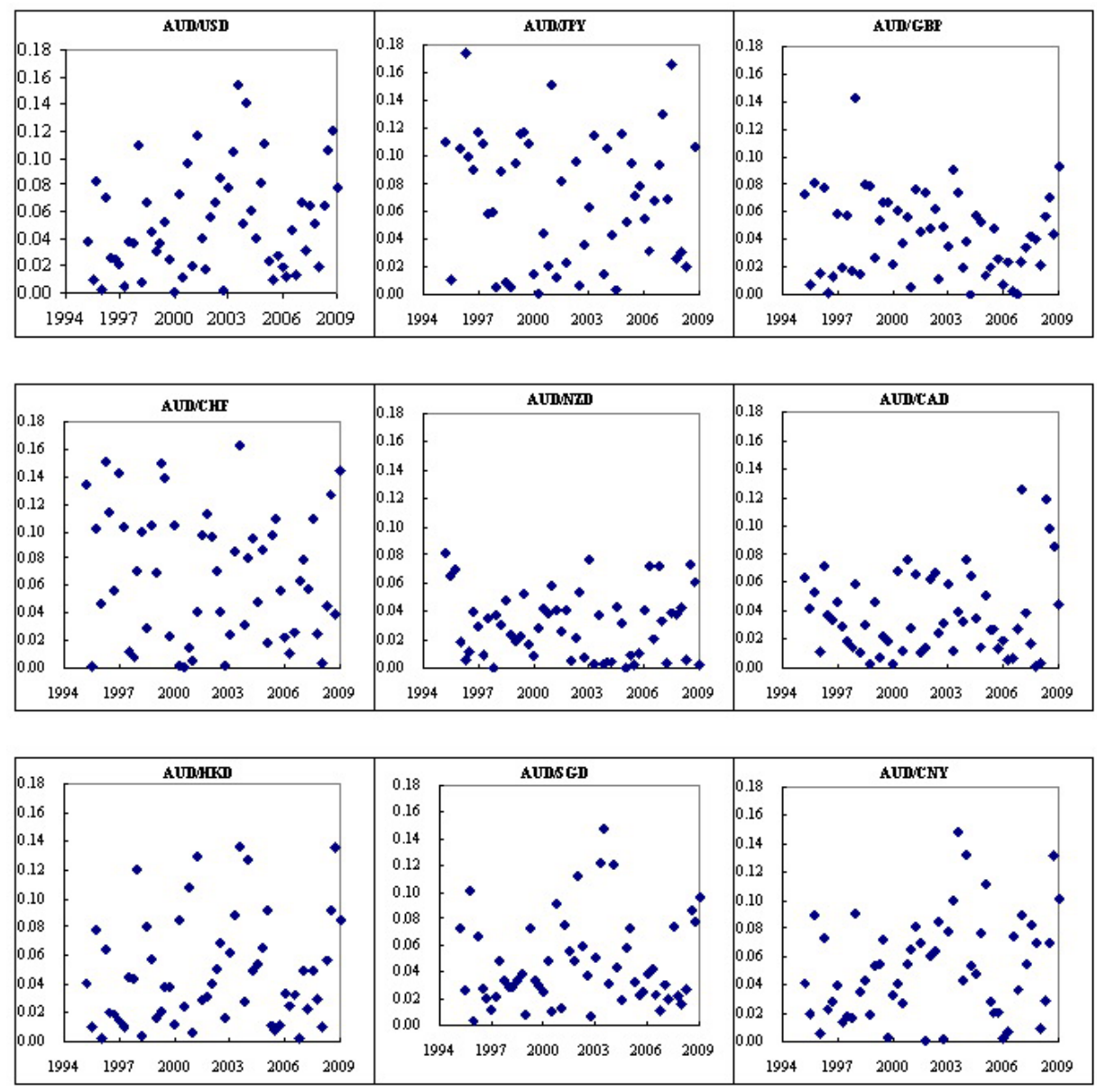
This result is also supported by regression outputs in Table 5. Unsurprisingly, five out of nine pairs have positive slopes. For the other four pairs whose slopes are negative, the slopes are merely below -0.0001. In fact, for all of the nine currency pairs, only one pair had the slope greater than 0.001 or less than -0.001 . However, just because the average slope is close to zero does not suggest the relationship between IRP's quality and years is stable. The R-square for the nine currency pairs only averaged to 0.01 , meaning the observations are poorly explained by the equation. In other words, the forecast errors tend to move randomly without obvious trends despite of which year the forecast is performed. Therefore it is concluded that the quality of IRP in forecasting exchange rates is not affected by years and the second $\mathrm{H}_{\mathrm{A}}$ holds.

\section{Table 5: Regression Output for Plots of Absolute Error over the period 1} April 1995 to 31 December 2008.

$\begin{array}{lllll} & \text { Obs } & \text { Intercept } & \text { Slope } & \text { R-squared } \\ \text { AUD/USD } & 57 & 0.0380 & 0.0005 & 0.0402 \\ \text { T-stats } & & -96.64 & -3342.97 & \\ \text { AUD/JPY } & 57 & 0.0863 & -0.0002 & 0.0017 \\ \text { T-stats } & & -53.84 & -1964.95 & \\ \text { AUD/GBP } & 57 & 0.0517 & -0.0003 & 0.0287 \\ \text { T-stats } & & -120.04 & -4220.68 & \\ \text { AUD/CHF } & 57 & 2.9454 & -0.0014 & 0.0165 \\ \text { T-stats } & & 0.65 & -669.86 & \\ \text { AUD/NZD } & 57 & 0.0338 & -0.0001 & 0.0066 \\ \text { T-stats } & & -156.02 & -5376.94 & \\ \text { AUD/CAD } & 57 & 0.0327 & 0.0002 & 0.0107 \\ \text { T-stats } & & -124.50 & -4291.08 & \\ \text { AUD/HKD } & 57 & 0.0400 & 0.0003 & 0.0126 \\ \text { T-stats } & & -95.99 & -3332.50 & \\ \text { AUD/SGD } & 57 & 0.0415 & 0.0002 & 0.0061 \\ \text { T-stats } & & -108.11 & -3758.82 & \\ \text { AUD/CNY } & 57 & 0.0372 & 0.0005 & 0.0586 \\ \text { T-stats } & & -103.05 & -3569.58 & \end{array}$

\section{Analysis of Empirical Results}

According to empirical evidence, the first null hypothesis is accepted (ie. IRP generally holds well). It was found that IRP also holds for emerging markets such as China. This is contrary to the previous literature findings that in developing markets with high transaction costs and low liquidity, IRP is expected to work 
poorly (Frankel and Poonawala, 2004). However, it is notable that among the ten main currencies we examined, CNY is the only one in a emerging market. So we cannot conclude that IRP holds in emerging markets.

The second null hypothesis is rejected (ie. there is no trend of IRP getting better recently). The average R-square of less than 0.01 means this is significant evidence. Also, all of the nine currency pairs have R-squares close to zero. This means no trends exist in any countries, no matter whether they are marketbased or bank-based, developed or developing countries. This is probably because interest rates in many countries have been frequently altered recently to recover the economy from recession. A famous example of government or bank manipulation would be Sweden's Riksbank which became the first to set its interest rate below zero in July 2009 (Picerno, 2009). The recession has also raised political risk by increasing the potential of currency crisis. Rising political risk also lies in the fact the investors in different countries may value their domestic and foreign investment risks differently. Thus, a lack of improvement in forecast accuracy in recent years is probably due to the recession. Finally, it must be noted that we assumed forward parity always holds and ignored differential tax laws in our research. As a result, it could be the case that after relaxing the assumption that $\mathrm{E}\left[\mathrm{S}_{\mathrm{t}}^{\mathrm{d} / \mathrm{f}}\right]=\mathrm{F}_{\mathrm{t}}^{\mathrm{d} / \mathrm{f}}$, or after taking differential tax laws into consideration, empirical results will show that CIRP has improved recently.

\section{Conclusion}

To conclude, regarding three-month horizons and major currency pairs in the world, IRP generally works well in forecasting exchange rates, but it does not work better now than in previous years. This reflects that the markets for the major currencies are relatively efficient for IRP to work, while recent recessions and government intervention have deteriorated the quality of IRP. However, these findings are based on the forward parity. The fact that settlement in the foreign exchange market may occur with time lags is not taken into consideration. Also, by equalizing bid and ask rates of exchange, transaction costs are ignored. Further investigations that relax the above assumptions would be fruitful.

\section{Acknowledgment}

We are indebted to Dr. Christropher Bilson at the Australian National University for his valuable comments. 


\section{References}

Alexius, A. 2001, 'Uncovered Interest Parity Revisited', Review of International Economics, 9(3), 505-517.

Chaboud, A.P. and J. H. Wright, 2003, ‘Uncovered Interest Parity: It Works, But Not For Long', International Finance and Discussion Papers (January).

Chinn, M.D. 2006, 'The (Partial) Rehabilitation of Interest Rate Parity in the Floating Rate Era: Longer Horizons, Alternative Expectations, and Emerging Markets', Journal of International Money and Finance, 25(1), 7-21.

Chinn, M.D. and G. Meredith, 2004, 'Monetary Policy and Long- Horizon Uncovered Interest Rate Parity', IMF Staff Papers, 51(3), Washington D.C.

Chinn, M.D. and G. Meredith, 2005, Testing Uncovered Interest Parity at Short and Long Horizons during the Post-Bretton Woods Era, National Bureau of Economic Research (NBER) Working Paper No. 11077.

Cochrane, J. 1999, New Facts in Finance, Economic Perspectives, Federal Reserve Bank of Chicago, XXIII (3), 3rd quarter 1999.

Flood, R.P. and A.K. Rose, 1996, 'Fixes: Of the Forward Discount Puzzle', Review of Economics and Statistics, 78(4), 748-752.

Flood, R. and M. Taylor, 1997, 'Exchange Rate Economics: What's Wrong with the Conventional Macro Approach?' in J.A. Frankel, G. Gali, and A. Giovannini, (eds), The Microstructure of Foreign Exchange Markets, Chicago, Chicago University Press, 262-301.

Frankel, J.A. and J. Poonawala, 2004, 'The Forward Market in Emerging Currencies: Less Biased than in Major Currencies', Journal of International Money and Finance, 29(3), 585 - 598.

Froot, K.A. and R.H. Thaler, 1990, 'Foreign Exchange', Journal of Economic Perspectives, 4(3), 179-192.

Mehl.A and Cappiello.L, 2007, Uncovered Interest Parity at Distant Horizons Evidence on Emerging Economies \& Nonlinearities, European Central Bank Working Paper Series No.801/ Aug 2007.

Mussa, M. 1979, Empirical Regularities in the Behavior of Exchange Rates and Theories of the Foreign Exchange Market, Carnegie-Rochester Conference Series on Public Policy, Vol. 11, 9-57. 
The ANU Undergraduate Research Journal Volume Two 2010

Picerno, J. 2009, 'Sweden Experiments with Negative Interest Rates', retrieved 30 September 2009, from http://seekingalpha.com/article/159202-swedenexperiments-with-negative-interest-rates.

Zhang, Y. 2006, 'Does the Horizon Matter? - The Uncovered Interest Parity Reconsidered', International Journal of Applied Economics, 3(2), 61-79. 